\title{
ARtiGO ORIGANAL A pesquisa em mídia e religião no Brasil: articulações teóricas na formação de uma área de estudos
}

Media AND RELIGION StUdies IN BRAZIL: THEORETICAL OUTLINES IN THE ORIGINS OF A RESEARCH FIELD

\section{Luis Mauro Sa Martino}

Professor do Mestrado em Comunicação da Faculdade Cásper Líbero. Doutor em Ciências Sociais pela PUC-SP. lmsamartino@gmail.com

\section{Resumo}

Este trabalho delineia trilhas da pesquisa em Mídia e Religião, focalizando a aproximação desses estudos com a área de Comunicação. A pesquisa focaliza os livros sobre o tema publicados entre 1980 e 2013. São delineados três momentos, não isentos de mesclas e sobreposições: (a) investigações a partir das Ciências Sociais, em particular da Sociologia da Religião; (b) primeiras articulações nos estudos sobre comunicação eclesial; e (c) a consolidação do tema na área de Comunicação. Observa-se como mídia e religião se articulam na produção de conhecimento no campo das pesquisas em Comunicação.

Palavras-chave: Mídia e Religião. Epistemologia. Teoria da Comunicação.

\section{Abstract}

This paper outlines some of the main research trends in media and religion, stressing the approachment of these studies with the Communication field. The research is grounded on the analysis of books published between 1970 and 2013. Three aspects were identified: (a) the investigation grounded on the Social Sciences, particularly Religion Sociology; (b) the first joint studies on ecclesial communication; and (c) the consolidation of the subject as part of the Communication field. It was observed how media and religion are articulated in the production of knowledge in Communication research field.

Keywords: Media and Religion. Epistemology. Communication Theory. 
As pesquisas sobre mídia e religião vêm ganhando considerável espaço na produção contemporânea da área de Comunicação. A publicação de livros, artigos e monografias em diferentes espaços acadêmicos, bem como a realização de eventos específicos indicam a vitalidade de um tema que se desenvolve em inúmeras ramificações no mundo social, indicando trilhas e caminhos para a investigação.

A observação inicial das publicações sobre o assunto indica, nesse sentido, a varidade nas articulações entre objetos empíricos e aportes teórico-metodológicos. Assim como outras temáticas vinculadas à área de Comunicação, como "Comunicação e Política" ou "Comunicação e Educação", cada uma com suas especificidades, a pesquisa sobre mídia e religião constitui-se como espaço de intersecção epistemológica, haurindo referenciais de diversas origens - cf. por exemplo, os estudos de Gomes (2004), Fausto Neto (2004), Borelli (2009) e Martino (2012).

No entanto, a vinculação dessa temática à área de Comunicação não aconteceu de um momento para outro. As articulações entre "mídia e religião", em toda sua variedade, e os estudos de Comunicação parecem resultar de um processo de aproximação epistemológica, não destituído de tensionamentos, na constituição de um olhar específico da área.

O objetivo deste texto é pontuar alguns aspectos da articulação da temática "mídia e religião" nos estudos de Comunicação a partir de uma origem que pode ser situada, cronológica e epistemologicamente, nas Ciências Sociais. A partir de pesquisa bibliográfica, tomando como corpus os trabalhos publicados na forma de livro entre 1980 e 2010 , observa-se de que maneira a temática "mídia e religião" se delineia como foco específico de investigação a partir, em um primeiro momento, das pesquisas de caráter sociológico e/ou antropológico para ganhar espaço como tema da Comunicação.

São recortados três momentos: (1) o predomínio da investigação tangencial sobre mídia no âmbito das Ciências Sociais; (2) as articulações iniciais com a área de Comunicação, em estudos sobre Comunicação Eclesial; (3) o desenvolvimento contemporâneo, com apropriações teórico-metodológicas correntes na área de Comunicação. Vale observar, de início, que essa divisão não deve ser vista como seccionamento, mas como aproximação, não isenta de mesclas, tensões e sobreposições.

\section{Problematizar as possíveis genealogias}

O delineamento de genealogias na área da produção de conhecimento traz em si uma série de riscos e questionamentos, dos quais decorre, inicialmente, a demanda por ressalvas a respeito dos parâmetros e limites dentro dos quais se procura verificar algumas

$82 \frac{\text { Comunicação \& Inovação, PPGCOM/USCS }}{\text { v. 15, n. } 29 \text { (81-93) jul-dez } 2014}$ 
relações, continuidades e rupturas em uma perspectiva diacrônica de desenvolvimento de um assunto, temática ou foco de investigação específico.

A formulação de genealogias, no campo acadêmico, não parece estar desprovida do sentido de busca por vínculos que, a partir do estabelecimento de uma ordem de continuidade específica, possam garantir a legitimidade de uma temática ou área do saber a partir do revestimento pelo manto da autoridade anterior reivindicado na naturalização de uma ligação indicada como recurso metodológico.

Não seria talvez de todo errado indicar, com Bourdieu (2001) ou Foucault (2003), que os objetos de investigação têm uma história permeada de linhas de força responsáveis pelos direcionamentos, tensões e singularidades responsáveis por delinear suas características. Na medida em que a observação de todas as variáveis envolvidas no processo ultrapassaria os limites de um artigo, e talvez mesmo de uma investigação epistemológica, busca-se aqui delinear pontualmente momentos particulares desse movimento.

Dessa maneira, a especificação de eventuais vínculos e continuidades não pode deixar de ser vista como "uma" relação possível entre outras, sem a pretensão de estabelecer "a" relação de continuidade, sob o risco de se perder as sutilezas e complexidades de um processo talvez inapreensível.

E, mais ainda, observar que o lugar de fala é estabelecido "de dentro", como participante interessado no diálogo, e de maneira alguma com a pretensão de indicar externamente as soluções de continuidade e ruptura entre áreas do saber. Finalmente, vale ressaltar que a indicação de "trânsitos" ou "articulações" indica apenas um movimento de elaboração epistemológica de uma temática a partir de referenciais diferentes, sem implicar na valoração dos resultados específicos do tipo de investigação desta ou daquela área.

Se, em uma observação genérica, seria possível sugerir um movimento desssa temática de um posto secundário e tangencial nas pesquisas sobre religião nas Ciências Sociais até seu protagonismo na área de Comunicação, a sustentação empírica desse postulado acarreta uma série de problemas quando se leva em consideração não apenas o desenvolvimento do tema, mas também a gênese das dinâmicas da área. Nesse sentido, seria quase um truísmo indicar que uma temática como "mídia e religião" tende a encontrar guarida dentro de uma área indicada como "Comunicação".

Nesse aspecto, é interessante, talvez, lembrar que as condições de apropriação de um tema por uma área do saber não estão dissociadas das condições de institucionalização dessa área, bem como das políticas que presidem a sua formação ou mesmo das linhas de força internas existentes na delimitação dos objetos de conhecimento. Se não é possível reduzir o epistemológico ao político, igualmente não é possível descartar as interferências de elementos políticos na formação dos olhares e objetos de uma área. 


\section{A mídia no estudo sociológico da religião}

A religião sempre foi uma das temáticas privilegiadas nas Ciências Sociais. Se a investigação filosófica a respeito do tema poderia remontar a uma tradição ainda mais complexa e distante no tempo, algo que ultrapassaria os limites deste trabalho, vale ressaltar que desde a formação das Ciências Sociais nota-se um interesse em compreender a religião como um fenômeno social no âmbito dos estudos a respeito da sociedade. Os chamados “pais fundadores” das Ciências Sociais, Marx, Weber e Durkheim, dedicaram considerável quantidade de estudos ao tema, incluindo aí algumas de suas obras clássicas.

Os múltiplos caminhos trilhados por esses estudos, no entanto, parecem trazer como unidade subjacente a preocupação em estudar a religião como um "espaço", "prática" ou "campo" específico, de maneira que suas relações com outros aspectos da sociedade nem sempre são levadas em consideração - ou, quando o são, é no sentido de se pensar a relação com outras dinâmicas sociais objetivadas no sentido de intersecções com a política, a economia, identidades ou vínculos comunitários. Nesse primeiro momento, a presença das temáticas vinculadas à "mídia" ou à "comunicação" não aparece senão de maneira subreptícia, considerando-se, em geral, uma noção bastante ampla de "comunicação" como sinônimo de "relação social" ou "conhecimento" - algo explícito, por exemplo, nos trabalhos de Berger e Luckmann (1988).

Os caminhos do fenômeno religioso, ao menos até os anos 1950, encontram-se com o espaço midiático de maneira apenas esporádica. Certamente é possível indicar a presença da mídia nos espaços religiosos desde o início das chamadas "comunicações de massa", no começo do século XX, mas traçar essa origem seria um exercício alheio a este texto.

No entanto, embora seja possível fazer essas menções, é possível delimitar os anos 1950 como o momento de um crescimento nas relações entre mídia e religião a partir do surgimento dos chamados "televangelistas" nos Estados Unidos. Como lembra Bruce (1990), embora os "radioevangelistas" já existissem, e houvesse uma profusão de publicações religiosas impressas bem antes da metade do século passado, é a partir do surgimento de programas religiosos na televisão que as atenções são atraídas para essa intersecção.

De fato, embora religiosos como o bispo católico Fulton Sheen e o pastor evangélico Billy Graham, ambos norte-americanos, tenham iniciado suas pregações através da televisão já nos anos 1950, os estudos acadêmicos sobre religião parecem ter demorado para se dar conta desse novo aspecto do fenômeno, até então desconhecido - cf. Smart (1999). É sobretudo a partir dos anos 1990, quando o campo religioso já está permeado 
de atividades relacionadas à mídia, que se nota um crescimento nas investigações sobre o tema, lembram Budenbaum (2002) e Stout e Budembaum (2002; 2008).

A delimitação da "Sociologia da Religião" como área relativamente autônoma dentro das Ciências Sociais parece ter implicado, em alguma medida, o fechamento em torno de questões específicas relacionadas as suas particularidades, de maneira que elementos exógenos, como a mídia, não constituiam suas preocupações principais, ao menos nesse momento.

É possível dizer, na esteira de Bourdieu (1987) e Pierucci (1996), que se trata de um movimento de autonomização que parte de uma "sociologia religiosa", isto é, praticada por religiosos no sentido de se entender, de um ponto de vista comprometido institucionalmente, questões de caráter particular, para uma "sociologia da religião", pensada por investigadores laicos no contexto de outros fenômenos sociais que merecem ser compreendidos em sua especificidade, como o esporte, a moda ou o consumo. No caso brasileiro, a constituição de uma área de investigação sociológica da religião acontece na virada dos anos 1960 para os 1970, a partir de estudos consagrados à chamada "sociologia religiosa".

A desvinculação da "sociologia da religião" dos estudos de caráter religioso parece ter sido fundamental para a emergência de uma área de "mídia e religião" na medida em que a inclusão de outras instâncias, no caso a comunicação, passa a ser possível e desejável na constituição de formas específicas de ação religiosa.

Nesse sentido, os estudos desenvolvidos em universidades e espaços laicos de investigação destacam-se pelo olhar lançado aos problemas da mídia. Trabalhos publicados nesse período sugerem essa aproximação inicial.

Em seu estudo pioneiro sobre o pentecostalismo em São Paulo, Beatriz Muniz de Souza (1969, pp. 117-132) já destacava o espaço preponderante da mídia, em especial das publicações e programas de rádio, como parte integrante das igrejas evangélicas, identificada como parte central de suas atividades, seja de manutenção dos laços estabelecidos com os fiéis, seja como parte das estratégias de proselitismo. Seu trabalho destaca, sobretudo, o uso dos meios de comunicação agregados às denominações religiosas, que por sua vez, atuam tanto como proprietárias de editoras e veículos impressos quanto como locatárias de espaços em rádios, esboçando uma relação de caráter institucional e econômico entre mídia e religião que se adensaria com o tempo.

A intersecção entre mídia e religião parece receber seus primeiros trabalhos monográficos, ainda na área da Sociologia da Religião, apenas nos anos 1980, quando a temática da "igreja eletrônica" ganha considerável espaço na agenda de pesquisa da área.

O estudo paradigmático de Hugo Assmann (1986), intitulado “A igreja eletrônica e seu impacto na América Latina" faz, ao que tudo indica pela primeira vez, um recorte

$$
\frac{\text { Comunicação \& Inovação, PPGCOM/USCS }}{\text { v. 15, n. } 29 \text { (81-93) jul-dez } 2014} 85
$$


específico a respeito das consequências políticas do televangelismo, sobretudo no que diz respeito à introdução de novas sensibilidades religiosas no contexto latino-americano, uma vez que o modelo de televangelismo era originário dos Estados Unidos - cf. Alexander (1997) -, contrastando com o catolicismo, até então predominante na América Latina, e com o protestantismo tradicional estabelecido no continente - é o tempo das "multinacionais da fé", como denomina Silletta (1988).

No entanto, essa vertente não parece ter frutificado Assim, estudos posteriores como os de Bolan (1972) sobre a secularização, Rolim (1980) sobre a religião popular, Maduro (1980) sobre a luta de classes ou mesmo Mendonça (1984), sobre as origens do protestantismo brasileiro, mencionam a mídia de maneira oblíqua no âmbito de suas temáticas. Estudos como os de Pierucci e Prandi (1996), Campos (1997) e Mariano (1999) sobre o Pentecostalismo católico e protestante, não sublinham os aspectos da mídia senão no âmbito de outras dinâmicas. As investidas católicas no campo midiático, em especial no televisivo, são tardias, constituindo, para usar as palavras de Oro (1996), a "reação católica", responsáveis por gerar, por exemplo, estudos sobre "padres cantores", como Souza (2005).

No entanto, apesar desses desenvolvimentos, é possível dizer que o tema da mídia manteve-se marginal no estudos de Sociologia da Religião. Pesquisas posteriores, seja no âmbito do Brasil ou da América Latina, igualmente deram espaço para as relações entre mídia e religião como elemento tangencial dentro de investigações voltadas para outros objetivos. Ao mesmo tempo, esse desenvolvimento parece ter chamado a atenção dos investigadores da área de Comunicação, sobretudo a partir dos anos 1980, no momento da inclusão desse objeto.

\section{A religião como objeto da pesquisa em comunicação}

Embora sua apropriação, como notado, seja particularmente tardia, datando sobretudo dos anos 1980 - quando a pesquisa em Comunicação já tinha, em si, uma tradição de pesquisa situada ainda nos anos 1960 -, o tema esteve presente em diversos trabalhos preocupados em conhecer, ou reconhecer, uma dimensão propriamente comunicacional nas questões vinculadas à religião. É possível notar, em um delineamento panorâmico no qual se perdem voluntariamente as sutilezas, uma alteração no olhar constituinte do objeto.

Se as investigações em Sociologia da Religião buscavam a observação da mídia como uma das dimensões presentes no fenômeno religioso institucionalizado, por sua vez, nas pesquisas em Comunicação, a questão metodológica incluía as perguntas a

$86 \frac{\text { Comunicação \& Inovação, PPGCOM/USCS }}{\text { v. 15, n. } 29 \text { (81-93) jul-dez } 2014}$ 
respeito das modalidades de operação da mídia dentro das instituições religiosas, a "mídia religiosa", em termos de objetivos, de condições de operação e funcionamento, de eficácia e de características da mensagem eclesiástica mediada.

Em outras palavras, seria possível afirmar que, na área de Comunicação, os estudos sobre mídia e religião nascem caudatários da pesquisa sobre "Comunicação Eclesiástica", concentradas, por sua vez, em estudos a respeito do catolicismo, em suas diversas acepções e movimentos, e dos chamados protestantismos "tradicionais - cf. Melo (1985; 1986). Nesse espaço, as discussões de Brose (1980), Gomes (1987) e Soares (1988), bem como as de Puntel (1994), procuram situar a comunicação elesiástica, sobretudo a católica, no contexto de redemocratização e expansão midiática - algo semelhante ao sentido proposto por Melo (1983) ao mencionar a passagem da "pesquisa-denúncia" para a "pesquisa-ação".

É possível localizar elementos dessa intersecção em estudos sociológicos, como um trabalho de Ortiz (1980) sobre religiosidades populares e Indústria Cultural, ou mesmo um texto anterior de Kolakowski (1977) sobre a presença de traços religiosos na cultura popular (entendida no sentido anglo-saxônico de "popular culture").

É possível destacar o trabalho de Beltrão (1980) sobre "folkcomunicação", no qual se dedica, em quase metade do livro, a estudar as formas de comunicação de grupos religiosos. Essa perspectiva parece estar, por exemplo, atrelada a trabalhos como os de Soares (1980), Riva (1980) e Fernandes (1980) - para um estado da questão na época, cf. Berbary (1983).

As relações com a religião parecem residir, em certa medida, nas relações fundantes do estabelecimento da área como espaço dotado de legitimidade e reflexão parcialmente autônoma. Assim, em um ponto de vista, coloca-se o Cristianismo, ao lado do Marxismo, como integrante das "matrizes" do pensamento em comunicação na América Latina - cf. Melo (2002) e Gomes (2004).

Em perspectiva histórico-crítica, Pedro Gilberto Gomes (2004, p. 211) delineia as conquistas dessas duas matrizes no espaço acadêmico de desenvolvimento original de um pensamento crítico, combinado às especificidades da região como fonte de uma reflexão na qual se procuram caminhos de reflexão não apenas do fenômeno religioso, mas também da própria comunicação.

Não seria, talvez, errado observar que a esse movimento da igreja Católica nos anos 1970 e 1980 corresponde, em termos históricos, o crescimento das igrejas neopentecostais, responsáveis por uma grande investida no campo midiático que tende igualmente a se revestir de importância para que se pensem as relações entre "mídia e religião" a partir de um ponto de vista especificamente comunicacional - cf. Mariano (1997).

$$
\frac{\text { Comunicação \& Inovação, PPGCOM/USCS }}{\text { v. 15, n. } 29 \text { (81-93) jul-dez } 2014} 87
$$




\section{Pensar mídia e religião desde a Comunicação}

A essa alteração nas dinâmicas do campo religioso são correlatas, por sua vez, as transformações da área de Comunicação. Em linhas gerais, o advento da Internet, nos anos 1990, assim como a expansão das mídias digitais, trouxeram novas perspectivas para o estudo das relações entre mídia e religião, apropriadas já a partir de um referencial da Comunicação. Há, aqui, uma ressalva preliminar a se fazer: a amplitude de expansão recente dos estudos de mídia e religião, somadas às limitações de espaço de um artigo demandam necessariamente escolhas que poderão implicar eventuais omissões - creditadas aos limites, de modo algum ao preterimento, com a evidente possibilidade, a partir do diálogo, de revisão e desdobramento futuro.

Os anos 2000 testemunharam, tanto no âmbito brasileiro quanto no internacional, um considerável crescimento no número de estudos a respeito de mídia e religião vinculados, seja a partir de relações epistemológicas ou institucionais, à área da Comunicação. Estudos sobre o tema assumiram inúmeras formas, seja no que diz respeito à pluralidade de objetos, seja nos aportes teóricos com eles relacionados - veja-se as coletâneas organizadas por Borelli (2010) e Melo, Gobbi e Endo (2007).

Observa-se, em termos panorâmicos, a tendência na adoção de referenciais presentes na área de Comunicação. Se não há um abandono dos referenciais de viés sociológico, há certamente a busca de uma contribuição específica da Comunicação a partir de alguns de seus referenciais teóricos - ainda que objetos, eles mesmos, de disputa (cf. Martino, 2008; 2011). Nota-se também a chegada de aportes oriundos de várias vertentes das "Teorias da Comunicação", como os derivados da Semiótica, como Nöth (1996) ou do Marketing, Campos (2002). Ao mesmo tempo, perspectivas teóricas específicas da área de Comunicação são trabalhadas por pesquisadores. Veja-se, por exemplo, as interfaces desenvolvidas com as questões do espetáculo, do entretenimento e do consumo expressos, a título de exemplo, nas produções de: Dias (2001), Gomes (2004), Fausto Neto (2004), Rodrigues e Dantas (2013), Patriota (2008; 2013), Carranza (2011) e Cunha (2011; 2013).

É possível também mencionar uma apropriação das relações entre mídia e religião pensada como parte de processos sociais mais amplos nos quais tanto a religião quanto a comunicação estão inseridas. Em termos empíricos, encontra-se também uma progressiva entrada das mídias digitais e dos ambientes da internet como objetos de estudo, secundados por bibliografia específica que se somam aos estudos sobre a chamada "comunicação de massa" - cf., por exemplo, os trabalhos de Martino (2003) e Klein (2005).

Sbardelotto (2012), por exemplo, dedica-se a estudar as especificidades dos meios técnicos digitais na constituição de formas particulares de manifestação do fenômeno 
religioso. Por sua vez, Miklos (2012) investiga as formas de elaboração e acionamento dos vínculos religiosos, pensados também em seu sentido de um "religare" a partir de diversos panos de fundo, no ciberespaço, tensionado com o espaço físico, ou "não virtual".

Isso não significa o abandono dos trabalhos dirigidos ao estudo das mídias de massa, em particular da televisão - veja-se, por exemplo, o estudo de E. C. Souza (2013) sobre a evangelização católica televisiva em âmbito urbano.

Como recorda Livingstone (2009), referindo-se ao espaço de pesquisas internacional, nota-se igualmente uma busca em não trabalhar "mídia", "religião" e "sociedade" como compartimentos estanques, mas pensá-los em uma ótica de intersecção de processos sociais "mediados" - no sentido de uma "ação da mídia" - pelos diversos ambientes digitais nos quais indivíduos, grupos e instituições estão inseridos. No mesmo sentido, os textos de Hjarvard $(2008$; 2012) apontam para os problemas constitutivos desses fenômenos na midiatização da sociedade.

Essas perspectivas vêm encontrando espaço particular de desenvolvimento nas pesquisas, por exemplo, de Borelli (2010; 2012), Fausto Neto (2004; 2006; 2008), Gomes (2002; 2006; 2010), Fiegenbaum (2006), Gasparetto (2011), Martino (2012; 2013), entre outros. As pesquisas desenvolvidas a partir dessas referências não parecem focar as relações entre "mídia" e "religião" como compartimentos estanques, mas observar as processualidades existentes no fenômeno religioso enquanto parte de uma sociedade em midiatização.

A apropriação contemporânea da temática "mídia e religião" nos espaços de pesquisa em Comunicação ultrapassa, em medida considerável, qualquer perspectiva anterior no sentido de se pensar em uma temática voltada para esta ou aquela singularidade. A adoção do tema pela área parece ter significado, igualmente, a intersecção das questões teórico-metodológicas da Comunicação, realçadas por uma contínua pluralidade.

\section{Considerações finais}

Um dos principais índices da vinculação da temática mídia e religião à Comunicação é o fato desses estudos compartilharem, atualmente, as ambivalências epistemológicas da área.

A pluralidade de referenciais, objetos e procedimentos metodológicos na pesquisa em mídia e religião pode ser vista, nesse sentido, como forma diferente de apropriação verificada nos espaços de investigação da Comunicação. Não se pode deixar de lado, nesse sentido, a possibilidade de estabelecer uma relação entre a progressiva vinculação de pesquisas sobre o tema à área de Comunicação à expansão, institucional e dos debates 
epistemológicos, verificada na própria área. Ao lado do crescimento, de certa maneira, é possível esperar também ramificações, e talvez esse seja um dos fatores responsáveis pelo crescimento numérico e temático das pesquisas em mídia e religião a partir dos anos 2000.

Além disso, é possível, igualmente, apontar uma diversificação do fenômeno religioso-midiático a partir desse período. Se era possível, em linhas bastante gerais, observar certo descompasso da igreja Católica em relação a suas contrapartidas neopentecostais no que tange ao uso da mídia, seja de massa ou digital, como parte integrante de suas práticas e mesmo de sua identidade, o final dos anos 1990 mostrou uma nova forma de religiosidade midiática católica objetivada no fenômeno dos "padres cantores", bem como de formas novas de transmissão televisiva e on-line de suas práticas. Ao mesmo tempo, nos espaços neopentecostais, foi possível, igualmente, observar mudanças no sentido de trabalhar lógicas específicas de vinculação com o entretenimento e com a cultura midiática contemporânea - cf. Martino (2013). O coeficiente de estudos dedicados às relações entre mídia e outras religiosidades parece se apresentar como numericamente menor, sendo possível destacar, por exemplo, os trabalhos de Signates (2010) dedicados à comunicação do Espiritismo. Religiões afro-brasileiras ou de origem semita, eventualmente por seu baixo índice de interesse em aspectos midiáticos, parecem igualmente não ocupar o mesmo destaque das pesquisas sobre católicos e evangélicos.

Do mesmo modo, a presença da religião na política parece ter sido igualmente acentuada no período da democratização, não como um interlocutor em si privilegiado, mas como ator de igual peso na constituição dos debates de uma esfera pública que, embora conserve seus princípios laicos, não se faz impermeável aos argumentos religiosos desde que, como recorda Habermas (2006), em texto sobre religião, obedecendo aos padrões de racionalização discursiva que possibilitam o debate.

A especificação de qualquer genealogia estaria além da medida em um texto deste teor, bem como talvez indicassem uma pretensão cuja realização demandaria um esforço empírico, documental e interpretativo consideravelmente grande.

No entanto, se é possível pensar que a constituição dos saberes não escapa, em si, a transformações, continuidades e rupturas dentro de sua história específica, é possível pontuar alguns aspectos dessa história e, mais ainda, procurar algum tipo de análise interpretativa do que pode constituir, mais do que uma "gênese", eventuais vínculos, quase afinidades eletivas, em uma área de pesquisa em desenvolvimento que, como inúmeras outras, parece encontrar seu maior desenvolvimento na pluralidade e no diálogo - objetivo, talvez, de qualquer pesquisa.

$90 \frac{\text { Comunicação \& Inovação, PPGCOM/USCS }}{\text { v. 15, n. } 29 \text { (81-93) jul-dez } 2014}$ 
A pesquisa em mídia e religião no Brasil: articulações teóricas na formação de uma área ...

\section{Referências}

AleXAnder, B. C. “Televangelism: redressive ritual within a larger social drama”. In: Hoover, S. \& LundBy, K. Rethinking Media, Religion and Culture. Londres: Sage, 1997.

Assmann, H. Igreja Eletrônica e seu impacto na América Latina. Petrópolis: Vozes, 1986.

Beltrão, L. Folkcomunicação. São Paulo: Cortez, 1980.

Berbary, A. “A pesquisa sobre comunicação religiosa”. In: Melo, J. M. Pesquisa em Comunicação no Brasil. São Paulo: Cortez/Intercom, 1983.

Berger, P. \& Luckman, T. “La Sociologia de la religion y la Sociologia del Conocimiento”. In: RoBERTSON, R. Sociologia de la religion, México, Fondo de Cultura Económica, 1990.

Bolan, V. Sociologia da Secularização, Petrópolis: Vozes, 1972.

Borelli, V. "Midiatização, dispositivo e os novos contratos de leitura geram uma outra religião". Biblioteca On-line de Ciências da Comunicação, v. 2010, p. 1-15, 2010.

. "Os sentidos do religioso e do midiático por fiéis da Igreja Internacional da Graça de Deus”. Líbero (FACASPER), v. 15, n. 29, p. 125-134, jun. de 2012.

Bourdieu, P. Choses Dites. Paris: Minuit, 1987.

Bruce, S. Pray TV: Televangelism in America. Londres: Routledge, 1990.

BuddenBAum, J. "Social Science and the study of media and religion: going forward by looking backward". Journal of Media and Religion. 1(1), 2002.

CAmpos, L. S. Marketing e religión: las estratégias de supervivencia de organizaciones religiosas en América Latina. In: VVAA. Religión y Postmodernidad. Quito: Aby-Yala, 2002.

. Teatro, templo e mercado. Petrópolis: Vozes, 1997.

Carranza, B. Catolicismo Midiático. Aparecida: Ideias e Letras, 2011.

Cunha, M. N. “O lugar das mídias no processo de construção imaginária do 'inimigo’ no caso Marco Feliciano". Comunicação, Mídia e Consumo, v. 10, p. 51-74, 2013.

. "Pentecostalismo e movimento ecumênico: aproximações e divergências". Estudos de Religiao (IMS), v. 24, p. 33-51, 2011.

DANTAS, J. G. "O comportamento dos telespectadores diante da programação televisiva neopentecostal”. Protestantismo em Revista. v. 16, mai-ago, 2008.

DiAs, A. P. Domingão do Cristão. São Paulo: Salesianas, 2001.

Fausto Neto, A. "Nada tira, nada envolve, nada completa - Leituras em recepção do discurso midiático religioso". FAMECOS, v. 1, p. 98-104, 2008.

. “A religião teleterapeutizante: discursividades dos templos midiáticos". Revista Fronteira (UNISINOS), São Leopoldo, v. 6, n. 2, p. 25-46, 2004a.

. “A Igreja Doméstica: estratégias televisivas de construção de novas religiosidades”. Cadernos IHU. Ano 2, número 7. São Leopoldo: Unisinos, 2004b.

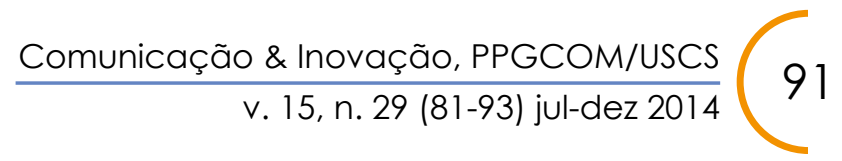


. "Dispositivos de tele-cura e contratos da salvação". Comunicação, Mídia e Consumo v. 3, p. 11-36, 2006.

Fiegenbaum, R. Z. "Midiatização do campo religioso: tensões e peculiaridades de uma relação de campos". UNIrevista - v. $1, \mathrm{n}^{\circ} 3$, julho 2006)

Figueiredo Filho, V. Entre o púlpito e o palanque. São Paulo: Annablume, 2005.

Gasparetto, P. R. Midiatização da religião. São Paulo: Paulinas, 2011.

Gomes, P. G. Da Igreja Eletrônica à sociedade em midiatização. São Paulo: Paulinas, 2010. . "O verbo se faz palavra: uma tautologia com sentido". Comunicação \& Sociedade, São Bernardo do Campo, v. 23, n. 37, p. 163-165, 2002.

. “Comunicação eclesial católica - reflexões inconclusas". In: Melo, J. M. \& GobBi, M. C. (Orgs). Pensamento comunicacional latino-americano. São Bernardo do Campo: Ed. Metodista, 2004a. . Da igreja eletrônica à sociedade em midiatização. São Paulo: Paulinas, 2010.

. "Processos midáticos e construção de novas religiosidades". Cadernos IHU-Ano 2, número 8. São Leopoldo: Unisinos, 2004b.

. Cultura, meios de comunicação e Igreja. São Paulo: Loyola, 1987.

Habermas, J. "Religion in the public sphere". European Journal of Philosophy 14:1, Cambridge: Polity, 2006.

KLeIN, A. Imagens de culto e imagens da mídia. Porto Alegre: Sulina, 2005.

Kolakowski, L. "A revanche do sagrado na cultura profana”. Religião e Sociedade, n.1, Maio 1977, pp. 153-165.

Maduro, O. Religião e Luta de Classes. Petrópolis: Vozes, 1981.

Mariano, R. Neopentecostais. São Paulo: Loyola, 1997.

Martino, L. M. The mediatization of religion. Londres: Ashgate, 2013.

. "Mediação e midiatização da religião em suas articulações teóricas e práticas: um levantamento de hipóteses e problemáticas". In: Mattos, M. H. \& JACKS, N. Mediação e Midiatização. Livro do XXI Compós. Salvador: Ed. UFBA, 2012.

. Mídia e Poder Simbólico. São Paulo: Paulus, 2003.

Melo, J. M. Comunicação: direito à informação. Campinas: Papirus, 1986.

. Comunicação: teoria e política. São Paulo: Summus, 1985.

. "Da pesquisa-denúncia à pesquisa-ação". In: . Teoria e pesquisa em comunicação. São Paulo: Cortez/Intercom, 1983.

Melo, J. M.; Gobbi, M. C. \& Enzo, F. Mídia e Religião na Sociedade do Espetáculo. São Bernardo do Campo: Editora da Universidade Metodista, 2007.

MendonçA, A. G. O celeste porvir. São Paulo: Paulinas, 1984.

MıкLos, J. Ciber-religião: a construção de vínculos religiosos na cibercultura. Aparecida: Ideias e Letras, 2012.

$92 \frac{\text { Comunicação \& Inovação, PPGCOM/USCS }}{\text { v. 15, n. } 29 \text { (81-93) jul-dez } 2014}$ 
A pesquisa em mídia e religião no Brasil: articulações teóricas na formação de uma área ...

Miranda, J. Carisma, Sociedade e Política, Rio de Janeiro: Relume-Dumará, 1999.

Nöтн, W. "Semiótica da Magia”. Revista USP, n. 31, , pp. 30-42, set-nov. 1996.

Oro, A. P. Avanço pentecostal e reação católica. Petrópolis: Vozes, 1997.

Ortız, R. "Religiões Populares e Indústria Cultural”. Religião e Sociedade, n. 05, , pp. 51-62, junho 1980.

Patriota, K. “Ensinando sobre o amor inteligente”. História Agora, v. 13, p. 282-299, 2013.

. "Mídia e Entretenimento: Em Busca da Religiosa Audiência". REVER v. 1, p. 69-88, 2008.

. "O fragmentado sujeito pós-moderno e a religião midiática". Revista Brasileira de História das Religiões, v. 1, p. 14, 2008.

Pierucci, A. F. Interesses religiosos dos sociólogos da religião. In: Oro, Ari Pedro \& Steil, A. C. Globalização e Religião. Petrópolis: Vozes, 1997.

Pierucci, A. F. de Oliveira \& Prandi, R. A Realidade Social das Religiões no Brasil. São Paulo: Hucitec, 1996.

Prandi, R. Um sopro do espírito. São Paulo: Edusp, 1997.

Puntel, J. T. Comunicação. São Paulo: Paulinas, 2010.

. A igreja e a democratização da comunicação. São Paulo: Paulinas, 1994.

Riva, P. "Suplicantes no caminho de aparecida". In: Melo, J. M. Comunicação e Classes Subalternas. São Paulo: Cortez, 1980.

Silletta, A. Multinacionales de la fé. Buenos Aires: Contrapunto, 1988.

Smart, J. "The Evangelist as Star: The Billy Graham Crusade in Australia, 1959”, Journal of Popular Culture, n. 33, pp. 165-73, 1999.

Soares, I. O. "Boletins diocesianos católicos". In: Melo, J. M. Comunicação e Classes Subalternas. São Paulo: Cortez, 1980.

. "Evolução das políticas de comunicação da Igreja Católica". In: Gomes, P. G. \& PIvA, M. C. Políticas de Comunicação. São Paulo: Paulinas, 1980.

SouzA, A. Igreja in Concert. São Paulo: Annablume, 2005.

SouzA, B. M. de A Experiência da Salvação - Pentecostais em São Paulo, São Paulo: Duas Cidades, 1969.

SouzA, E. C. Igreja na cidade. São Paulo: Paulinas, 2013.

Stout, D. \& Buddenbaum, J. "Genealogy of an Emerging Field: Foundations for the Study of Media and Religion”. Journal of Media and Religion 1(1), 2002.

. "Approaches to the study of media and religion: Notes from the Editors of the Journal of Media and Religion with recommendations for future research". Religion 38 (2008) 226-232. 